\title{
Social Media, Rumors, and Hurricane Warning Systems in Puerto Rico
}

\author{
Lily Bui, PhD candidate \\ MIT Department of Urban Studies \& Planning \\ LilyBui@MIT.edu
}

\begin{abstract}
Disaster warning systems are a form of risk communication that allow national, state, and local actors to prepare for, respond to, and understand disaster risk. The increased use of social media platforms to exchange information around disasters challenges traditional, centralized forms of risk communication. While social media is already used in emergency management to some degree, issues of trust and reliability of information limit the widespread adoption of social media into emergency management practices. This paper offers a case study of the role that social media information plays in Puerto Rico's hurricane early warning system and highlights the affordances and limitations of decentralized, heterarchical communication forms around disasters for federal, state, and local-level emergency management authorities. The case highlights differences in perception of social media information around disasters by emergency management authorities and by community members both before and after Hurricane Maria in 2017.
\end{abstract}

\section{Introduction}

Lessons from major disaster events of the past have highlighted that the capacity of a community to reduce risk can be increased with availability of timely information exchange, and feedback processes across jurisdictions and sectors [23]. Increasingly ubiquitous and persistent connectivity, particularly in urban centers, means that since the 2010 Haitian Earthquake, such informal networks are now commonplace in response to disaster, and are especially prevalent in the absence of formal information sources showing realtime hazard information [16][20]. However, during major disaster events such as Hurricane Irma and Hurricane Maria, research finds that residents do not always receive targeted warning when it is needed the most due to delays in response, lack of access to information or the inability for people to receive timely warnings through the appropriate communication channels [29].

Of particular relevance, internet-connected smartphones and social media networks catalyze the creation of informal networks for communication and coordination of information in response to natural disasters [23][24][25]. Currently, disaster management processes do not routinely facilitate the integration of these networks into disaster response activities [25]. Further, there are no established protocols for sharing time-sensitive data on government/agency response activities in machine-readable formats that can be readily consumed by social media applications to and share these with community networks [12][14]. A knowledge gap exists to understand how community generated networks can contribute to formal disaster management processes, and how in return, response agencies can improve processes for capturing information generated by community networks for disaster management and risk reduction.

Social media networks like Facebook, Twitter, YouTube, and Instagram are increasingly a source of information and news for people worldwide. They can be used to convey information during disasters to send warnings, to conduct situational awareness, and even to catalyze action and sustain feedback loops among public authorities, volunteer groups, the business sector, and citizens. The wide spectrum of social media platforms and the overwhelming volume of content being circulated on each platform at any given time make for a "data avalanche" that can be challenging for decision makers and responders to manage during disasters [40].

No two social media platforms are the same and each attracts its own audience of users and offers its own means of communicating information. While some platforms allow users to share a combination of photographs and text, others may privilege video as the main type of content. Some platforms automatically tag posts with geospatial information while others do not. Houston et. al (2015) have developed a framework for social media use in disaster planning, response, and research and in so doing have identified fifteen distinct 
ways in which individuals use social media to talk about a disaster incident.

Uses of social media range from providing preparedness information before the disaster occurs, to sending and receiving requests for assistance during the disaster, to helping reconnect community members post-disaster. One of the major concerns of relying on social media information during a disaster is that of propagating misinformation during critical phases of disaster response [2] [40] [41]. On the one hand, having access to such a large amount of information on social media before, during, and after a disaster can be advantageous for assessing need, therein lies the problem of sifting verifiable, useful information from erroneous, misleading information. Regardless, given the dearth of information that becomes available on social media around disaster incidents, there has been much speculation about how social media information may be incorporated into disaster warning systems.

Previous research has examined the uses of social media during both natural [24] and man-made disasters [38] and the degree to which general users of social media trust information being produced on social media platforms. However, less research has been produced about the effect of more decentralized, heterarchical risk communication platforms like social media on more centralized, hierarchical risk communication platforms. There is a need to understand to what extent social media information augments, challenges, or obfuscates official communication channels around disasters.

This paper offers a case study that closely examines the role of social media information within Puerto Rico's hurricane early warning system. The circumstances under which this study was carried out involve a "natural experiment": Hurricane Maria during the 2017 Atlantic hurricane season. The first phase of this study involved interviews that investigated how disaster managers and community members on the island perceived of the use of social media before the hurricane, and the second phase of the study follows up on whether attitudes changed or not after the hurricane.

In making sense of the findings, his paper's principal objectives are to answer the following questions: How do perceptions of social media information around disasters differ between emergency management authorities and community members? Did this change after the passage of Hurricane Maria in 2017?

\section{Social Media in Early Warning Systems}

The purpose of an early warning system ("EWS") is to provide information concerning potential natural disasters to decision makers across sectors (government, NGOs, private sector, civil society, et al.) so that they might work to minimize risk to life and property prior to, during, or after the manifestation of disasters [50][36][27][22][46][5]. For this reason, early warning systems are a key component of disaster management; they allow for information to reach those who will be affected by disaster.

Within a typical early warning system, an actor monitors and gathers data about existing conditions; sends that data to a central location to be analyzed, produces forecasts based on that data; and then sends appropriate warnings to decision makers, responders, and at-risk populations [49]. In the event of a hurricane, for instance, a hydro-meteorological authority might use satellites to collect data about developing storms; aggregate and analyze the data from a common database; produce forecasts about a storm's trajectory and magnitude; and send warnings about its potential impacts to decision makers, responders, and at-risk populations. Because the effectiveness of early warning systems depends upon the accuracy of scientific data, existing research often characterizes EWS by their technological infrastructure and reliance on scientific knowledge [44]. However, a more holistic understanding of early warning systems must also take into account the fact that EWS are not merely technocratic, organizational constructs but also social constructs. That is to say, EWS are constituted and executed by human actors [18][11]. For instance, a hurricane early warning system may consist of advanced remote sensing technology and software that can predict a storm's trajectory and magnitude, but it is also constituted by the people who manage the technology and make decisions based on the data produced by the technology. Thus, the effectiveness of warning systems depends not only on the technical information they are able to provide but also on who participates in them.

Social media serves as a source of intelligence and local knowledge during disasters, capturing the reactions, concerns, and observations of those affected by the disaster through text and images. A "humans as sensors" approach places even more emphasis on the observations of people for data collection [13][51]. Viewing social media as a type of warning system 
during disasters extends the idea that people can be sensors of their environments and can convey relevant and timely information within communication networks when disasters occur.

\subsection{Hierarchical and heterarchical risk communication forms}

Traditionally, risk communication constructs such as warning systems operate using a hierarchical, oneway mode of information transfer in which gatekeepers selected what information to share with the public [41]. Then, risk and crisis communication in the 1960s and 1970s placed more emphasis on the variable perceptions that the public can have about the same information, leading to overreaction and mistrust at worst. In the 1990s, this unidirectional model of risk and crisis communication was criticized and further decentralized to make room for multiple means of communicating the same information in different ways [52].

Unlike the traditional "one-to-many," centralized model of emergency management communication systems, social media allows for "many-to-many," decentralized communication across peer networks [26][12]. However, disaster and emergency planning still revolves around the conventional unidirectional model of information dissemination during disasters [41]. Tapia \& Moore (2014) argue that disaster managers' critiques of of social media's reliability, verifiability, and trustworthiness are unreasonable. Their study finds that disaster managers already operate with less-than-reliable information in the field, and that emergency managers use social media information during response phases from their known community and network. Importantly, the study concludes firmly that trust first begins with people, not data. The barriers to adopting social media into disaster management practice are therefore institutional. Other research has expressed criticism against the inflexibility of disaster managers with regard to interfacing with the public to gather information about disaster incidents [54][7][29][14]. The distinction between hierarchical and heterarchical systems is discussed widely in management science and organizational theory [23][17][15][3].

\subsection{Precedents for social media use during disasters and emergencies}

Precedents for social media usage around disasters exist around the world. At the community and civic engagement level, there are examples like the 2007 southern California wildfires in Malibu, CA, which blazed for nearly twenty days across the region. Affected communities used social media platforms like mobile phones, photo sharing services like Flickr or Picasa, and Twitter as a backchannel for communicating with each other [41]. Chatfield \& Brajawidagda (2007) observe networks of people and organizations on Twitter who served as official and unofficial warning systems for a potential tsunami in Indonesia. Sakaki, Okazaki, \& Matsuo (2010) designed and developed a method for using tweets as earthquake early warning systems in Japan. During a recent terror attack in Manchester, UK, local residents of the affected city used the Twitter hashtag \#RoomForManchester in posts to indicate open rooms and shelters where affected individuals could stay in the short-term (Horton, 2017). At the level of decision makers and responders, there are examples like TweeTracker and CrisisTracker, tools designed to help first responders gain situational awareness of disasters from realtime tweets with the aid of data mining tools [20] [33]. PetaBencana is a platform for emergency response and disaster management in megacities in South and Southeast Asia. It began as a flood mapping platform in Jakarta, Indonesia, which allowed for individuals with social media accounts to report flooding in various parts of the city. The information would be mapped in real-time and made accessible to responders. Practitioners and researchers have also made a case for social media-based warning systems for disease detection, monitoring of outbreaks pandemics, and overall health surveillance [25][6].

\section{Case selection: Puerto Rico \& Hurricane Maria}

The Caribbean region is highly susceptible to hurricanes, and islands like Puerto Rico, located within the region, are highly susceptible to hurricanes and their impacts [48][21]. Given high level of exposure and likelihood to hurricanes, an effective warning system is necessary to reduce damage to life and property. Puerto Rico has dealt with multiple hurricane events in the past and thus invests planning efforts into managing the risks posed by natural disasters to its resources [7][4][33][30]. The last three major hurricanes that made landfall on the island before 
Hurricane Maria caused a total of 17 deaths (direct and indirect) and $\$ 3.7$ billion (USD) in damage to property and infrastructure. These hurricanes also passed close to San Juan, ultimately affecting the east side of the island more than the west side.

Hurricane Maria, a Category 4 storm, swept through Puerto Rico on September 20, 2017. With maximum wind intensity of 150 knots and storm surge up to 9 feet above the ground, it was one of the most powerful hurricanes to have ever hit the island [31]. The death toll is highly uncertain, although the official number stands at 65, which includes an unknown number of indirect deaths. ${ }^{1}$ The estimated cost in damages to Puerto Rico and the adjacent U.S. Virgin Islands hovers around $\$ 90$ billion USD [37]. The power grid was severely damaged, leading to islandwide blackouts that lasted months after the storm. In the immediate days after the hurricane made landfall, the extensive power outages also led to communications blackouts for those on phone networks that did not have backup power for their towers and antennae [31]. The blackouts also meant that Internet communications were down for an extended period of time, further challenging communications between people, organizations, and governments.

Emergency management authorities at the federal, state, and local levels in Puerto Rico are trained to employ best practices for hurricane warnings through traditional and official communication channels (i.e. media briefings, website, emergency management services channels). The use of social media by community members, media personalities, and amateur meteorologists to communicate about hurricanes and storms offers a way for people to communicate outside of official warning channels.

Social media usage in Puerto Rico has grown significantly over the years alongside mobile phone usage. A 2016 study from Estudios Tecnicos, an economic planning and consulting firm on the island, finds that nine out of every 10 people in Puerto Rico own a cell phone, and $68.2 \%$ of cell phones are smartphones. Additionally, $94.7 \%$ of internet users on the island reported that they connect to the internet through their phones, accessing social media platforms such as Facebook, WhatsApp, and YouTube [9].

\footnotetext{
${ }^{1}$ It should be noted that hundreds of additional indirect deaths in Puerto Rico may eventually be attributed to Maria's aftermath pending the results of an official government review.
}

Those working in emergency management have tried a number of strategies to mitigate the spread of rumors on social media, especially where social media information conflicts with official messaging. At the same time, community members express support for alternative communication channels like those available on social media given that they often reach more targeted audiences. Given the tension between differential attitudes toward the use of social media for risk communication on the island, Puerto Rico becomes a unique case to examine to better understand social media's affordances and limitations during disasters.

\subsection{The island context}

In addition, small, urbanized islands are cited as some of the most disproportionately vulnerable places with regard to exposure to natural hazards within international policy frameworks that address DRR such as the Sendai Framework for Disaster Risk Reduction and the United Nations Sustainable Development Goals [1][47][44]. Much has been observed about different centralized and decentralized risk communication strategies for managing early warning information [44]. Yet, existing scholarship mostly examines early warning [55][5] without many studies of specific islands and their local contexts. It is possible that case studies of specific islands can lead to best practices and learnings that can be applied to other island contexts.

\section{Methodology}

\subsection{Semi-structured interviews}

Over the course of one year between January 2017 and January 2018, 64 interviews were undertaken with individuals and groups across multiple sectors engaged with Puerto Rico's hurricane early warning system. These sectors included government (at federal, state, municipal levels), NGOs, universities, community organizations, military, media, and communities. Individuals were identified and selected based on their involvement with the process of formulating, disseminating, receiving, and acting upon hurricane early warning system information. Other interviewees were identified through snowball sampling during fieldwork. Of the interviewees, $35 \%$ were women and $65 \%$ were men. Many of the interviewees represented government organizations such as the National Weather Service, Federal Emergency Management Agency. Some represented 
non-governmental organizations like the Red Cross, local media, faith-based and community-based organizations. Community members included residents of San Juan.

Interviews were not conducted for attribution and informants are mainly referred to in the results section by their titles and roles as opposed to specific names. Ethics approval was obtained through the Massachusetts Institute of Technology human subjects research protocol (COUHES) before the study was conducted.

This data collection approach allowed for detailed, descriptive accounts of how hurricane early warning systems work, as well as "deeper dives" into the intersubjective experiences and interpretations of those who are affected [9][52]. I conducted some interviews in English and other interviews in Spanish where interviewees expressed higher level comfort in the Spanish language. Interviews typically lasted between 20 and 40 minutes and were conducted oneon-one. In rare instances during which I conducted group interviews, I would ask one question at a time, then give all interviewees an opportunity to answer the same question. The interview instrument was tested first with two key informants before being used for others. Some interviews were audio recorded, but the majority were recorded and transcribed via handwritten notes. Importantly, interviews were conducted both before and after Hurricane Maria to compare perceptions of social media usage during disaster both among emergency managers and community members. See Appendix for supporting files and interview instrument.

\subsection{Participant observation}

During field work associated with this study, I carried out a research fellowship with the Department of Natural and Environmental Resources (DNER) in Puerto Rico, a state-level government agency in charge of, inter alia, the management of natural resources in coastal areas. It also oversees the Puerto Rico Climate Change Council (PR-CCC), an interdisciplinary group of policy makers and researchers concerned with climate change adaptation plans on the island.

Being embedded in the field within a government office allowed me to gain access to interviewees through exposure to the DNER and PRCCC's social network. I also gained access to an annual conference called the Caribbean Regional Response Team meeting wherein 80 individuals representing several federal governmental organizations, including the military, involved with emergency response to disasters convened to set an annual agenda for the team. Through this relationship with the DNER, I participated in community planning meetings during which the main subject of discussion was climate change adaptation, which included community strategies for disaster risk reduction at a local level. Field notes were taken throughout this embedded field work and incorporated into the field data collected for this study. This model of "service learning" is based on an exchange between a researcher and community partner, creating an opportunity for researchers to make a local contribution while in the field [37][19].

\subsection{Document review}

Interviewees from multiple government agencies provided me with training materials that document Puerto Rico's early warning preparedness and response structures and timelines. I used these documents to corroborate findings from field interviews, and vice versa, during my analysis of Puerto Rico's early warning system structure. The documents included various organizational charts from the National Weather Service and Tsunami Warning Center in Puerto Rico, which described the flow of information during warnings, as well as the leadership chain of command during emergencies and disasters.

\subsection{Analysis approaches and limitations}

Audio and notes from all interviews were transcribed and translated to English using Microsoft Word. An a priori coding scheme was created in which interviewees were categorized by sector (e.g. "government") and sector type (e.g. "federal" or "state"). Responses for each interview question were logged for every interviewee, with these sector categories in mind. Then, an emergent coding scheme was created to further categorize major themes in the responses from interviewees. These coding schemes were also used to categorize notes from participant observation and document review.

Because the findings of this study are prone to intersubjectivity among interviewees and myself, the researcher, responses from the interviews were corroborated with each other, and follow-up interviews over the phone were conducted to clarify details in order to triangulate the data collected. Additional follow-up interviews with key informants were also conducted during April 2017 and January 2018 to validate the data collected in initial interviews, to 
mitigate the potential bias and intersubjectivity of the author from having been embedded in the DNER during field work, and to

The case study approach to San Juan offers a means of producing context-dependent knowledge in order to understand what factors influence complex events and processes like those that constitute hurricane early warning systems. However, the external validity of the study may be limited to island territories like Puerto Rico and not necessarily independent island states. This study was limited to San Juan, Puerto Rico, meaning that only the urban context was studied and represented. It is important to consider that the resources available for early warning in San Juan may not be as widely used or accessible in non-urban areas where information communications technology and infrastructure do not have extensive reach. For instance, some interview respondents indicated that communities in more rural areas of the island sometimes do not rely on television or the internet for news coverage. In addition, other groups that this study did not successfully reach and represent completely include marginalized populations such as prisoners and illegal immigrants.

\section{Findings}

\section{Pre-Hurricane Maria}

\subsection{Emergency management authorities mitigate social media misinformation by being responsive to} "rumors."

Dispelling rumors on social media is often one of the biggest weaknesses and challenges for "official" early warning actors upstream. The National Weather Service actively monitors weather-related social media accounts from amateur meteorologists who have large followings, but who ultimately do not have the final authority to declare when a tropical storm is officially a hurricane. In the case where the NWS has not officially declared a storm a hurricane, and a social media account uses the word "hurricane" explicitly in describing an oncoming storm, the NWS would use social media to respond to that post with the intent of clarifying the official message.

\subsection{The National Weather Service provides all warnings in English first, then Spanish.}

While the NWS does release early warning information in both English and Spanish, English is usually the primary language used to communicate, with Spanish translations following an hour or two afterward. Because the National Weather Service field office in San Juan, Puerto Rico, is responsible for monitoring and communicating with both Puerto Rico and the U.S. Virgin Islands (where the primary language is English), the warnings originating from the San Juan office must be in English first. The Spanish translations usually come out at least an hour after the English warnings.

\subsection{Emergency management authorities recognize a need to update risk communication practices to encompass new communication platforms.}

Many emergency managers who are responsible for warnings reported an awareness of the growing ubiquity of smartphones and social media. Many of the drills for Puerto Rico's early warning system rely on older forms of communication technology such as television, radio, phones, and in some cases Internet. In interviews, emergency managers noted a need to update testing of early warnings to be more inclusive of smartphone technology to reach more and more people.

\subsection{Native Spanish speakers are likely to rely on Spanish-language social media accounts for disaster information instead of more official channels like the National Weather Service.}

An overwhelming majority of Puerto Ricans speak Spanish (94.5\%), and a large majority self-report that they speak English "less than "very well"" (83.3\%) according to the 2011-2015 American Community Survey. Among residents in San Juan, whose primary language is Spanish, local Spanish-language media and social outlets are the main source for hurricane information as opposed to national media outlets, which mainly use English.

\section{Post-Hurricane Maria}

\subsection{Sustained loss of power during Hurricane Maria was unexpected by many in the emergency management community.}

Many emergency managers responsible for risk communication noted that substantial time was dedicated to testing equipment and communication channels before Hurricane Maria hit. However, the power grid failure after the hurricane made landfall caused all communications to fail. Additionally, there were no clear protocols for dealing with long-term power and communications loss. Many emergency managers relied on satellite phones and ham radios as a backup communication method, but this proved to be 
only partially effective, as neither functions well with too much cloud cover.

\subsection{Social media was used by emergency managers before Hurricane Maria made landfall to provide live updates on the storm's status.}

The National Weather Service, local media, and local meteorologists coordinated news briefings and social media messaging before Hurricane Maria hit. The objective was to provide a "unified voice" among risk communicators to give community members accurate updates about the storm. This was done in English and Spanish.

5.7. Social media was a faster way for emergency managers to translate warnings from English to Spanish before and during the storm.

Referring back to the pre-hurricane finding, the National Weather Service releases all warnings in English first, then translates them into Spanish through all the official NWS communications channels. This lag causes many native Spanish speakers to seek their news from other sources like Spanish-language social media accounts instead. However, for Hurricane Maria, the National Weather Service leaned on social media as a means of having one dedicated channel on which English and Spanish warnings could come out somewhat simultaneously. The translations were done much more quickly on social media and were able to reach people in a timely manner.

5.8. Community members reported relying on social media to communicate with each other after the storm.

The majority of community members interviewed reported using social media to communicate with one another whenever it became possible to do so. Although power and communications were out for up to months after the storm, sporadic connectivity allowed community members to use each other's phones to contact family members on the island and on the U.S. mainland. In some cases, community members reported that it was more efficient for them to use social media to contact friends or family on the mainland, in order to give them instructions about others to contact back in Puerto Rico, given the limited and less reliable connectivity on-island.

\section{Discussion \& Conclusions}

The role of social media in warning systems continues to become more prevalent, and emergency managers are finding new ways to integrate information on social media into their practices. While warning systems are designed to be hierarchical, meaning that there is a centralized authority or organization in charge of disseminating information to actors downstream, social media offers a more heterarchical means of communication between peer networks. While on the one hand, rumors and misinformation might spread through social media's informal networks, these same informal networks can provide a channel through which timely information can travel even more quickly and reach more people.

The emergency management community would benefit from seeking strategies that readily incorporate social media into the way that risk communicators both get and push out information before, during, and after disasters. While this study only captures one case, it provides a before and after view of how social media is used and perceived by emergency managers and community members around a significant natural disaster.

This study could be expanded to include other island communities to better understand whether similar challenges with social media, rumor control, and trust are consistent in the island context. Particularly in island communities in which different languages are spoken, it is important to consider the language access gaps in existing hierarchical warning systems and whether social media becomes a communication tool that circumvents existing language barriers.

Islands like Puerto Rico will unfortunately continue to experience disasters. Not only are islands in the Caribbean, Pacific, and Indian Oceans prone to cyclones and hurricanes, but they are also subject to other hazards such as earthquakes, tsunamis, volcanoes, sea-level rise, heat waves, droughts, nuclear accidents, and terrorism. The way in which warning systems are designed for island communities must be sensitive to their differential contexts, especially where language and culture can mean the difference between life and death. 


\section{References}

[1] Aitsi-Selmi, A., Egawa, S., Sasaki, H., Wannous, C., \& Murray, V. (2015) The Sendai framework for disaster risk reduction: renewing the global commitment to people's resilience, health, and well-being. International Journal of Disaster Risk Science, 6(2), 164-176.

[2] Alexander, D. E. (2014). Social media in disaster risk reduction and crisis management. Science and Engineering Ethics, 20(3), 717-733.

[3] Anderson, P. (1999) Perspective: Complexity theory and organization science. Organization science, 10(3), 216-232.

[4] Arbona, J. (2004) Vieques, Puerto Rico: From Devastation to Conservation, and Back Again.

MIT.

[5] Basher, R. (2006) Global early warning systems for natural hazards: systematic and people- centered. Philosophical Transactions of the Royal Society of London A: Mathematical, Physical and Engineering Sciences, 364(1845), 2167-2182.

[6] Brownstein, J. S., Freifeld, C. C., \& Madoff, L. C. (2009). Digital disease detection-harnessing the Web for public health surveillance. New England Journal of Medicine, 360(21), 2153-2157.

[7] Bush, D. M., Webb, R. M. T., Hyman, L., Liboy, J. G., \& Neal, W. J. (1995) Living with the Puerto Rico Shore. Durham, NC: Duke University Press.

[8] Chatfield, A., \& Brajawidagda, U. (2012). Twitter tsunami early warning network: a social network analysis of Twitter information flows.

[9] Estudios Tecnicos. (2016). Digital \& Mobile Behavioral Study. Retrieved from

https://www.estudiostecnicos.com/pdf/perspectivas/2016/ma yo2016.pdf. Accessed 30 August 2018.

[10] Flyvbjerg, B. (2006) Five misunderstandings about casestudy research. Qualitative inquiry, 12(2), 219-245.

[11] Glantz, M. H. (2003). Usable Science 8: Early Warning Systems: Do's and Don'ts. Shanghai, China: National Center for Atmospheric Research.

[12] Gonzalez-Herrero, A. \& Smith, S. (2008). Crisis communications management on the web: how internetbased technologies are changing the way public relations professionals handle business crises. Journal of Contingencies and Crisis Management, 16(3), 143-153.

[13] Goodchild, M. F. (2007). Citizens as sensors: the world of volunteered geography. GeoJournal, 69(4), 211-221.
[14] Granger-Happ, E. (2008). The Good Enough Principle What we can learn about technology from the pragmatic solutions of nonprofits. Save the Children, pp. 1-25.

[15] Hedlund, G. (1993) Assumptions of hierarchy and heterarchy, with applications to the management of the multinational corporation. In Organization theory and the multinational corporation (pp. 211-236). Palgrave Macmillan UK.

[16] Houston, J. B., Hawthorne, J., Perreault, M. F., Park, E. H., Goldstein Hode, M., Halliwell, M. R., \& Griffith, S. A. (2015). Social media and disasters: a functional framework for social media use in disaster planning, response, and research. Disasters, 39(1), 1-22.

[17] Ibarra, H. (1993) Network centrality, power, and innovation involvement: Determinants of technical and administrative roles. Academy of Management journal, 36(3), 471-501.

[18] Kelman, I., \& Glantz, M. H. (2014) Early warning systems defined. In Reducing disaster: Early warning systems for climate change (pp. 89-108). Springer Netherlands.

[19] Kendall, J. C. (1990) Combining Service and Learning. A Resource Book for Community and Public Service. Volume I. National Society for Internships and Experiential Education: Raleigh, NC.

[20] Kumar, S., Barbier, G., Abbasi, M. A., \& Liu, H. (2011). TweetTracker: An Analysis Tool for Humanitarian and Disaster Relief. In ICWSM.

[21] Lugo, A.E. (2000) Effects and outcomes of Caribbean hurricanes in a climate change scenario.

Science of the Total Environment. 262(3): 243-251.

[22] Manyena, S. B. (2006) The concept of resilience revisited. Disasters, 30(4), 434-450.

[23] Meier, P. (2007) New Strategies for Early Response: Insights from Complexity Science. Presented at the International Studies Association Convention, Tufts University.

[24] Mendoza, M., Poblete, B., \& Castillo, C. (2010). "Twitter Under Crisis: Can We Trust What We RT?" in Proceedings of 1st Workshop on Social Media Analytics (SOMA 2010), Washington, D.C: IBM Research, 71- 79. Retrieved from http://snap.stanford.edu/soma2010/papers/soma2010_11.pdf

[25] Merchant, R. M., Elmer, S., \& Lurie, N. (2011). Integrating social media into emergency-preparedness efforts. New England Journal of Medicine, 365(4), 289-291.

[26] Mills, A., R. Chen, J. Lee, and H.R. Rao (2009) 'Web 2.0 emergency applications: how useful can Twitter be for 
emergency response?'. Journal of Information Privacy and Security. 5(3). pp. 3-26.

[27] Norris, F. H., Stevens, S. P., Pfefferbaum, B., Wyche, K. F., \& Pfefferbaum, R. L. (2007). Community resilience as a metaphor, theory, set of capacities, and strategy for disaster readiness. American Journal of Community Psychology, 41(1-2), 127-150. https://doi.org/10.1007/s10464-007-91566.

[28] Organization of American States. (2014) Early Warning Systems in the Urban Setting - A Caribbean Perspective. Presented at the Sustainable Cities.

[29] Palen, L. \& Liu, S. (2007). Citizen Communications in Disaster: Anticipating a Future of ICT-supported Public Participation. In the Proceedings of the SIGCHI Conference on Human Factors in Computing Systems (CHI '07). ACM Press, NY, 727-736.

[30] Parker, D. J., Priest, S. J., \& Tapsell, S. M. (2009). Understanding and enhancing the public's behavioural response to flood warning information. Meteorological applications, 16(1), 103-114.

[31] Pasch, Richard J., Penny, Andrew B., \& Berg, Robbie. (2017). National Hurricane Center Tropical Cyclone report: Hurricane Maria. National Hurricane Center.

[32] Puerto Rico Climate Change Council. (2013) Puerto Rico's State of the Climate 2010-2013: Assessing Puerto Rico's Social-Ecological Vulnerabilities in a Changing Climate. San Juan, PR. Retrieved from http://prccc.org/download/PR\%20State\%20 \% \%20the\%20ClimateFINAL ENE2015.pdf.

[33] Rivera-Collazo, I., Winter, A., Scholz, D., Mangini, A., Miller, T., Kushnir, Y., \& Black, D. (2015). Human adaptation strategies to abrupt climate change in Puerto Rico ca. $3.5 \mathrm{ka}$. The Holocene, 25(4), 627-640. https://doi.org/10.1177/0959683614565951

[34] Rogstadius, J., Vukovic, M., Teixeira, C. A., Kostakos, V., Karapanos, E., \& Laredo, J. A. (2013). CrisisTracker: Crowdsourced social media curation for disaster awareness. IBM Journal of Research and Development, 57(5), 4: 1-4: 13.

[35] Sakaki, T., Okazaki, M., \& Matsuo, Y. (2010). Earthquake shakes Twitter users: real-time event detection by social sensors. In Proceedings of the 19th international conference on World wide web (pp. 851-860). ACM.

[36] Sellnow, T. L., \& Seeger, M. W. (2013) Theorizing crisis communication (Vol. 4). John Wiley \& Sons.

[37] Staletovich, Jenny. (2018). "Final numbers on Maria in Puerto Rico: $\$ 90$ billion in damage, some Cat 5 winds." Miami Herald. Retrieved from http://www.miamiherald.com/news/weather/hurricane/article 208350879.html. Accessed 3 May 2018.
[38] Stanton, T. K., Giles Jr, D. E., \& Cruz, N. I. (1999) Service-Learning: A Movement's Pioneers Reflect on Its Origins, Practice, and Future. Jossey-Bass Higher and Adult Education Series. Jossey-Bass Inc., Publishers, 350 Sansome St., San Francisco, CA 94104.

[39] Starbird et al., (2014). "Rumors, False Flags, and Digital Vigilantes: Misinformation on Twitter after the 2013 Boston Marathon Bombing," iConference 2014 Proceedings. 654 662, doi:10.9776/14308/

[40] Sui, D., \& Goodchild, M. (2011). The convergence of GIS and social media: challenges for GIScience. International Journal of Geographical Information Science, 25(11), 1737-1748.

[41] Sutton, J. N., Palen, L., \& Shklovski, I. (2008). Backchannels on the front lines: Emergency uses of social media in the 2007 Southern California Wildfires (pp. 624632). University of Colorado.

[42] Stern, Eric K. (2017). "Unpacking and Exploring the Relationship between Crisis Management and Social Media in the Era of 'Smart Devices'." Homeland Security Affairs 13, Article 4. Retrieved from https://www.hsaj.org/articles/13986.

[43] Tapia, A. H., \& Moore, K. (2014). Good enough is good enough: Overcoming disaster response organizations' slow social media data adoption. Computer Supported Cooperative Work (CSCW), 23(4-6), 483-512.

[44] Thompson, S. (2003) Report on Early Warning Systems in the Caribbean Region. Presented at the Hemisferic Consultation on Early Warning, Antigua, Guatemala.

[45] United Nations. (2017) Sustainable Development Knowledge Platform: Small Island Developing States. Retrieved

from https://sustainabledevelopment.un.org/topics/sids.

Accessed 21 March 2017.

[46] UNISDR. (2004) Small Island Developing States, Disasters, Risk and Vulnerability: Background Consultative Paper. Presented at the BPoA +10 Inter-regional Preparatory Meeting, Nassau, Bahamas: UNISDR.

[47] UNISDR. (2015) Sendai Framework for Disaster Risk Reduction 2015-2030. United Nations: Geneva, Switzerland.

[48] UN-OHRLLS. (2011) Small Island Developing States: Small Islands Big(ger) Stakes. Office of the High Representative for the Least Developed Countries, Landlocked Developing Countries and Small Island Developing States.

[49] USAID. (2017) Building an End-to-End Hydrometeorological Early Warning System. Document. 
[50] Villagran de Leon, J. C. (2012) Early warning principles and systems. Handbook of Hazards and Disaster Risk Reduction, Routledge, London, UK, 481-492.

[51] Wang, D., Amin, M. T., Li, S., Abdelzaher, T., Kaplan, L., Gu, S., \& Wang, X. (2014, April). Using humans as sensors: an estimation-theoretic perspective. In Information Processing in Sensor Networks, IPSN-14 Proceedings of the 13th International Symposium on (pp. 35-46). IEEE.

[52] Weiss, R. (1994) Learning From Strangers: The Art and Method of Qualitative Interview Studies. Free Press.

[53] Wendling, C., Radisch, J., \& Jacobzone, S. (2013). The use of social media in risk and crisis communication.

[54] Wenger, D. E., Quarantelli E.L. \& Dynes, R.R. 1990. Is the Incident Command System a Plan for All Seasons and Emergency Situations? University of Delaware, Disaster Research Center. Preliminary Paper \#215.

[55] World Meteorological Organization (WMO). (2017) Climate Risk and Early Warning Systems Prioritize the Most Vulnerable | YubaNet. Retrieved from http://yubanet.com/world/wmo-climate-risk-and-earlywarning-systems-prioritize-the-most-vulnerable 